\title{
In vitro $\mathrm{pH}$ dependent passive transport of ketoprofen and metformin
}

\author{
Alisa Elezović* ${ }^{1}$, Amina Marić ${ }^{1}$, Amila Biščević ${ }^{1}$, Jasmina Hadžiabdić ${ }^{1}$, Selma Škrbo ${ }^{2}$, \\ Selma Špirtović-Halilović ${ }^{3}$, Ognjenka Rahić ${ }^{1}$, Edina Vranić ${ }^{1}$, Amar Elezović ${ }^{4}$ \\ ${ }^{1}$ Department of Pharmaceutical Technology, Faculty of Pharmacy, University of Sarajevo, Zmaja od Bosne 8, 71000 \\ Sarajevo, Bosnia and Herzegovina \\ ${ }^{2}$ Department of Clinical Pharmacy, Faculty of Pharmacy, University of Sarajevo, Zmaja od Bosne 8, 71000 Sarajevo \\ ${ }^{3}$ Department of Pharmaceutical Chemistry, Faculty of Pharmacy, University of Sarajevo, Zmaja od Bosne 8, 71000 \\ Sarajevo, Bosnia and Herzegovina \\ ${ }^{4}$ Control laboratory of the Agency for Medicinal Products and Medical Devices, Titova 9, 71000 Sarajevo
}

*Corresponding Author: E-mail: alisa.elezovic@ffsa.unsa.ba; Tel.: +387-33-586-173; Fax: +387-33-586-180

Received: October 16, 2020; Revised: December 02, 2020; Published: December 09, 2020

\begin{abstract}
The kinetics of passive transport of ketoprofen and metformin, as model substances for high and low permeability, respectively, across the artificial membrane under the influence of the $\mathrm{pH}$ of donor solution was investigated. There was an upward trend in the apparent permeation coefficient $\left(P_{\text {app }}\right)$ of ketoprofen with the decrease in $\mathrm{pH}$ to a value close to $\mathrm{pKa}$. At the $\mathrm{pH}$ value below $\mathrm{pKa}$ the permeation coefficient had lower value, due to the higher retention of ketoprofen in the artificial membrane. Metformin is a low permeable compound, and the highest permeation values were recorded at $\mathrm{pH}$ 7.4. Two dissociation constants determine that metformin at physiological pH exists as a hydrophilic cationic molecule, i.e. predominantly in ionized form. At pH values below 2.8, metformin mainly exists in diprotonated form, and it was, thus, very poorly permeable. The highest retention, i.e. affinity of both ketoprofen and metformin to the membrane, was at the lowest $\mathrm{pH}$ values, which is explained by different mechanisms. At higher $\mathrm{pH}$ values of donor compartment the substances showed significantly less affinity to the membrane. The obtained values of apparent permeation coefficients at studied $\mathrm{pH}$ values showed good correlation with the obtained experimental values by other in vitro methods.
\end{abstract}

C2021 by the authors. This article is an open-access article distributed under the terms and conditions of the Creative Commons Attribution license (http://creativecommons.org/licenses/by/4.0/).

\section{Keywords}

dynamic diffusion cell model; artificial membrane; in vitro permeation; BCS II; BCS III

\section{Introduction}

The oral route is the most preferred route of drug administration. It is considered safe, effective, and readily available, with minimal discomfort to the patient compared to other routes [1]. The absorption of orally administered drugs is a function of its dissolution, solubility and permeability of the substance along the length of the gastrointestinal tract (GIT) [2]. The absorption of active substances varies depending on the $\mathrm{pH}$ along the gastrointestinal tract [3]. In general, the absorption of active substances mainly takes place in the small intestine, i.e. in the jejunum which has the largest absorption surface [4]. 
The Biopharmaceutical Classification System (BCS) categorizes drugs into four classes according to their water solubility and permeability across intestinal membrane. Based on the available data on low solubility and high permeability of ketoprofen, it belongs to class II (BCS II) [5], while metformin as a highly soluble and low permeable substance belongs to BSC class III [6].

Ketoprofen is a non-steroidal anti-inflammatory analgesic. Within the $\mathrm{pH}$ of the gastrointestinal tract, ketoprofen is an ionized substance (weak acid). The pKa value of ketoprofen is approximately 4.45 at $25^{\circ} \mathrm{C}$ [7].

Metformin is often described as an insulin stabilizer because, due to its positive effects on insulin acceptor and tyrosine kinase activity, it leads to a decrease in plasma insulin levels and insulin resistance [8]. Metformin has two different values of the dissociation constant, namely pKa 2.8 and 11.5, and as a result of which at physiological $\mathrm{pH}$ it exists as a hydrophilic cationic molecule. At $\mathrm{pH}$ values below 2.8 , it mainly exists in diprotonated form, and thus difficult to permeate. At pH values higher than 11.5 it is found in non-ionized form which is the most favorable form for passive transport across membranes [9], however this $\mathrm{pH}$ is not found physiologically.

Models for determining permeability are used in the early stages of drug discovery and development and are a major strategy to prevent drug rejections due to poor pharmacokinetics in the later, more expensive phases of clinical trials [10]. The most reliable way to determine the permeation of active substances is in vivo testing of human intestinal perfusion. However, due to simpler, faster and much less expensive performance compared to the in vivo tests, in situ, ex vivo and in vitro models are mainly used for permeation assessment [11].

In vitro methods are the most commonly used alternative for testing the permeation of active substances [12]. Depending on the biopharmaceutical class of the active substance, they may have a good correlation with the in vivo results [13]. Most active substances are absorbed by passive transport, so the application of in vitro methods using artificial membranes that mimic passive transport is considered an effective and reproducible method for assessing permeability [12], especially in screening stages of drug discovery.

Absorption, distribution, metabolism, excretion and toxicity are greatly influenced by the charge of the active substances at different $\mathrm{pH}$ conditions. Consideration of $\mathrm{pH}$ values in relation to other molecular properties is of great importance and has the potential to be used to further improve the efficacy of the application of active substances [14]. The method of permeation testing on artificial membranes, which could reliably predict the passive transport of the active substance as a function of $\mathrm{pH}$, would significantly facilitate the characterization of new candidate substances in the initial stages of drug development.

In this work, the kinetics of passive transport of ketoprofen (BCS II) and metformin (BCS III), as model substances for high and low permeability, respectively, across the artificial membrane under the influence of the $\mathrm{pH}$ value of the donor solution was investigated. The results were compared with the available literature data obtained by different permeation methods of these two substances.

\section{Experimental}

\section{Materials}

Deionized water was obtained on Arium 611, Sartorius (Sartorius Lab Instruments GmbH \& Co. KG, Göttingen, Germany). The materials used in this experimental work include: disodium hydrogen phosphate 
dihydrate (Kemika, Zagreb, Croatia), cholesterol (Sarajevolijek, Sarajevo, Bosnia and Herzegovina), potassium dihydrogen phosphate (Semikem, Sarajevo, Bosnia and Herzegovina), disodium hydrogen phosphate (Kemika, Zagreb, Croatia), ketoprofen, working standard (LEK, Slovenia), metformin hydrochloride, reference standard (Merck, Darmstadt, Germany), sodium chloride (Merck, Darmstadt, Germany), n-octanol (Semikem, Sarajevo, Bosnia and Herzegovina), hydrochloric acid (Lach-ner, sro Neratovice, Czech Republic), 85 \% phosphoric acid (Mallinckrodt Baker BV, Deventer, The Netherlands). Egg lecithin (Lipoid ${ }^{\circledR} \mathrm{E} 80$ ) was a kind gift from Lipoid GmbH, Ludwigshafen, Germany.

\section{Methods}

In the experimental work, the Instructions for use of the apparatus absorption simulator Sartorius Model SM 16750 (Sartorius Membranfilter GmbH, Germany) and the method of the authors Corti et al. $[1,15]$ and our study group [16] were used. Cellulose nitrate filter (mixed cellulose ester), pore size $0.45 \mu \mathrm{m}$ (Sartorius AG, Göttingen, Germany) was impregnated with $2 \mathrm{~mL}$ solution of $2.10 \%$ cholesterol and $1.70 \%$ egg lecithin (Lipoid ${ }^{\circledR} \mathrm{E}$ 80) in $\mathrm{n}$-octanol for 10 minutes. The excess impregnation solution was removed by pressing a filter located between the two absorbent papers. The mass of the filter before and after impregnation was determined using an analytical balance (AG 400, Metler Toledo GmbH, Switzerland) from which the percentage of impregnation solution retained on the filter was calculated as filter mass increase.

The filter prepared in this way was placed in a diffusion cell of absorption simulator connected to the donor and acceptor compartments. The donor compartment contained a solution of $500 \mu \mathrm{mol} \mathrm{L}^{-1}$ of active substance (ketoprofen or metformin) in $100 \mathrm{~mL}$ of phosphate buffer of different $\mathrm{pH}$ values. The $\mathrm{pH}$ values of the buffer in the donor compartment were: 7.4, 6.8, 4.5 and 3.0 or 2.0 for ketoprofen or metformin, respectively. Phosphate buffer of $\mathrm{pH} 7.4$ was present in the acceptor compartment in all experiments. The temperature in both compartments was measured and maintained at $37 \pm 0.5{ }^{\circ} \mathrm{C}$. Under the action of the peristaltic pump, the contents of the donor and acceptor compartment were constantly circulating through the diffusion cell on both sides of the membrane (Figure 1).

At 30, 60, 90 and 120 minutes, sampling was performed from the acceptor compartment and the concentration of active substances (ketoprofen or metformin) was determined spectrophotometrically. Spectrophotometric measurements were performed on UV-VIS spectrophotometer UV-1601 (Shimadzu, Kyoto, Japan). The method was validated prior to the permeation experiments according to ICH guideline Q2-R1 [17].

After reading the results on the spectrophotometer, the samples were returned to the acceptor compartment. At the end (120 minutes), the samples were also taken from donor compartment, and concentration of ketoprofen or metformin was determined spectrophotometrically. This data was used to calculate the recovery value $(R)$. Each experiment was performed in triplicate.

From the samples taken from the acceptor compartment, the apparent permeability coefficients of ketoprofen and metformin were calculated based on Equation 1:

$$
P_{a p p}=\frac{d Q}{d t} \frac{1}{A C_{0}}
$$

where $P_{\text {app }}$ - apparent permeation coefficient, $\mathrm{cm} \mathrm{s}^{-1} ; \mathrm{d} Q / \mathrm{d} t$ - mass of the substance that passed through the membrane per unit time, $\mathrm{mg} \mathrm{s}^{-1} ; A$ - effective surface of the artificial membrane through which the permeation was examined, $\mathrm{cm}^{2} ; C_{0}$ - initial concentration of active substance in donor solution, $\mathrm{mg} \mathrm{mL}^{-1}$. 


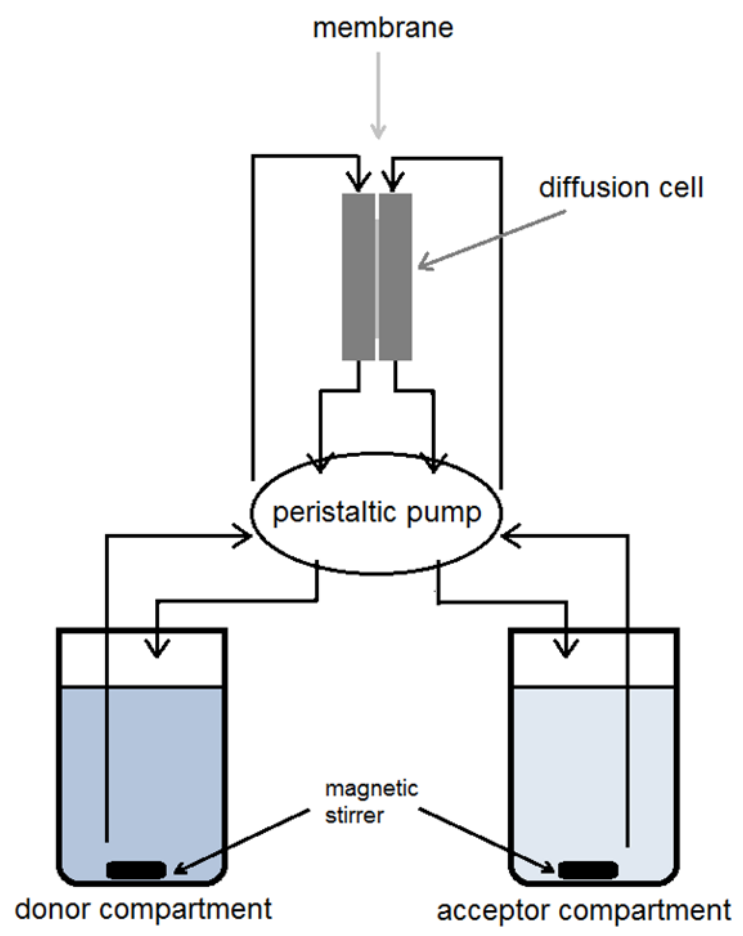

Figure 1. Absorption simulator Sartorius Model SM 16750

Recovery of ketoprofen and metformin (as a percentage of the substance not retained in the membrane) was determined according to Equation 2:

$$
R \%=\frac{C_{a, \text { end }} V_{a}+C_{d, \text { end }} V_{d}}{C_{d, 0} V_{d}} \times 100
$$

where $C_{\mathrm{a} \text {, end }}$ and $C_{\mathrm{d}, \text { end }}$ - concentration of test substance measured at the end of the experiment in acceptor and donor solution, $\mathrm{mg} \mathrm{mL}^{-1} ; C_{\mathrm{d}, 0}$ - initial concentration of test substance in donor solution, $\mathrm{mg} \mathrm{mL}^{-1} ; V_{\mathrm{a}}$ and $V_{\mathrm{d}}$ - volumes of acceptor and donor solution, $\mathrm{mL}$.

\section{Results and discussion}

Permeations of ketoprofen and metformin were monitored in this experimental work at different $\mathrm{pH}$ values of the donor compartment, while the $\mathrm{pH}$ of the acceptor compartment was 7.4 in all cases. In this way, it was possible to examine the permeation of the substances from the donor compartment at different $\mathrm{pH}$ values, which simulated GIT conditions across an artificial membrane embedded in a diffusion cell in the acceptor compartment that reflected the $\mathrm{pH}$ conditions of the systemic circulation.

A membrane filter with pore size of $0.45 \mu \mathrm{m}$ was used in this work. As we mentioned in the earlier work [16] the pore size of the membrane filter does not affect the permeability of active substances across the artificial membrane, since in Corti et al. [1] there was no clear causal relationship between $P_{\text {app }}$ and pore sizes established.

According to the Instructions for use of the apparatus (Sartorius Model SM 16750), the increase in filter weight after impregnation should be $100 \pm 5 \%$. The mean value of the percentage of impregnation of the membrane, i.e. the average increase in filter mass was $158.67 \pm 5.59 \%$. These values are similar to the values of experimental studies conducted by Corti et al. [1] and our study group [16]. According to both studies, the structure of a membrane filter that was not originally intended for use in this experiment is responsible for the larger increase in filter mass after impregnation. 


\section{Permeation of ketoprofen dependent on the $\mathrm{pH}$ of the donor solution}

The ketoprofen permeation profiles' parameters at different $\mathrm{pH}$ of the donor compartment are presented in Table 1 and Figure 2.

Table 1. Mean values $(n=3)$ of the apparent permeation coefficients $\left(P_{\text {app }}\right)$ of ketoprofen, the recovery of the substance not retained by the membrane $(R)$ and percentage of calculated (non)ionized species (HA/A) at different $\mathrm{pH}$ values of donor compartment.

\begin{tabular}{cccc}
\hline pH & $\boldsymbol{P}_{\text {app }}\left(\times 10^{-5} \mathbf{c m ~ s}^{-1}\right) \pm$ SD & $\boldsymbol{R}(\%) \pm$ SD & HA/A (\%) \\
\hline $\mathbf{7 . 4}$ & $6.95 \pm 0.51$ & $97.95 \pm 2.42$ & $0.11 / 99.89$ \\
$\mathbf{6 . 8}$ & $16.8 \pm 1.10$ & $87.83 \pm 2.77$ & $0.44 / 99.56$ \\
$\mathbf{4 . 5}$ & $41.6 \pm 1.67$ & $83.52 \pm 1.68$ & $47.17 / 52.83$ \\
$\mathbf{3 . 0}$ & $12.9 \pm 0.28$ & $51.91 \pm 1.79$ & $96.61 / 3.39$ \\
\hline
\end{tabular}

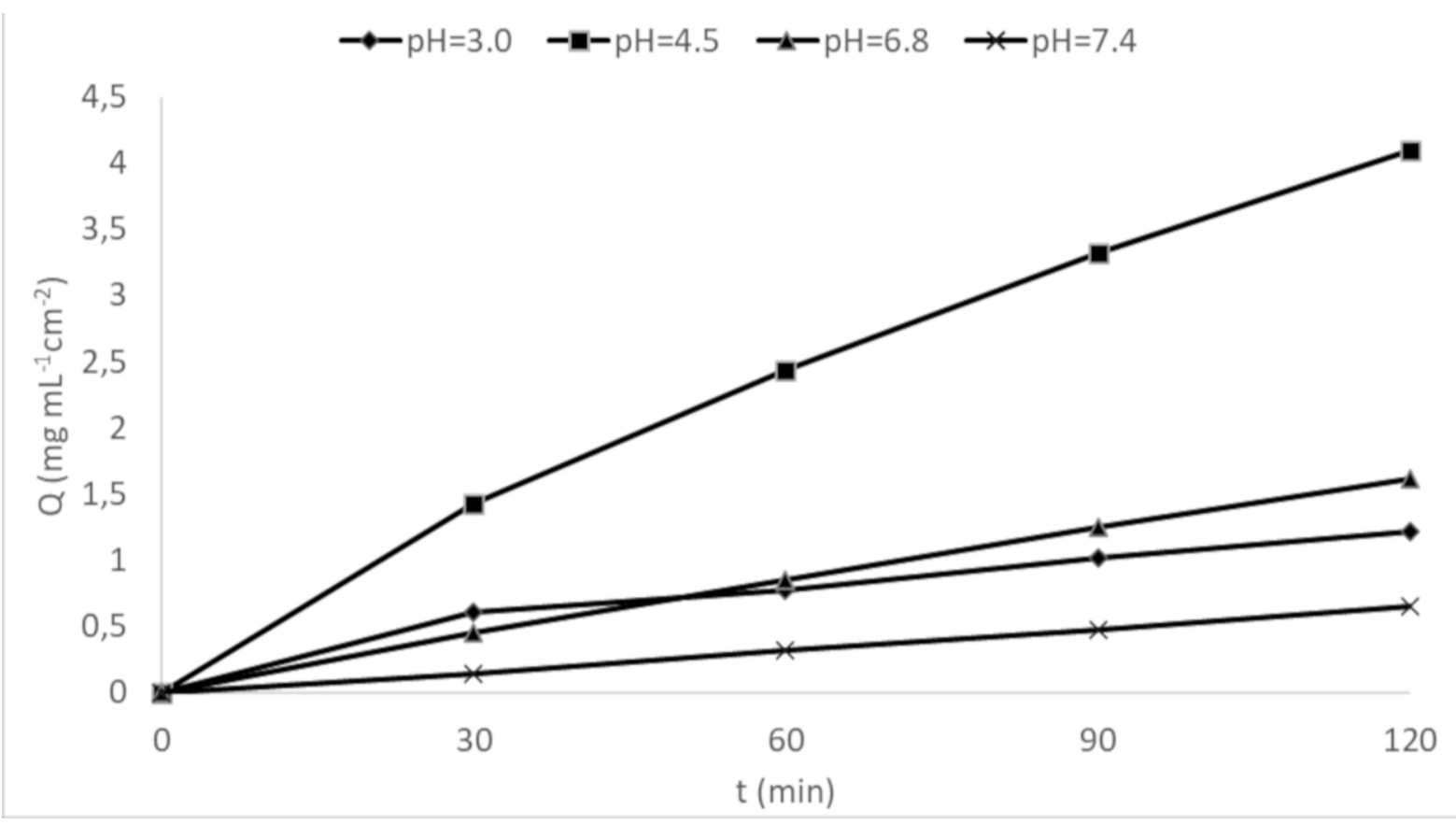

Figure 2. Overall permeated amount of ketoprofen through the artificial membrane at different $\mathrm{pH}$ values of donor compartment.

Large values of the apparent permeation coefficients confirm that it is a highly permeable substance. The low standard deviation of the apparent permeation coefficients shows good reproducibility of the method for highly permeable substances. The recovery values indicate whether ketoprofen was retained in the membrane, and this retention varied significantly depending on the $\mathrm{pH}$ value.

In general, ionized substances are better soluble, and non-ionized ones pass through the cell membrane better. The calculated percentage of non-ionized ketoprofen decreased from $96.61 \%$ for $\mathrm{pH}=3.0$ to 0.11 $\%$ at $\mathrm{pH}=7.4$ (Table 1 ). Ketoprofen is a weak acid and its maximum permeation is expected in areas where the $\mathrm{pH}$ value is close to the $\mathrm{pKa}$ of the substance, which in the case of ketoprofen is 4.45 , where there is $47.17 \%$ non-ionized ketoprofen. These obtained calculated values of the proportions of ionized and nonionized species explain the values of the apparent permeation coefficients and recovery factors at individual $\mathrm{pH}$, discussed below.

It can be seen from Figure 2 that the equilibrium permeation concentrations were not established at any $\mathrm{pH}$ during the 120 -minute test period. 
In general the values of $P_{\text {app }}$ in all $\mathrm{pH}$ media were high (Table 1). Such results indicate high permeability of ketoprofen, which is in line with the literature data showing that ketoprofen belongs to BCS class II.

The recovery value increased with increasing $\mathrm{pH}$ (Table 1), and for $\mathrm{pH}=7.4$ the recovery value was $97.95 \%$. Such a high value indicates that a very small percentage of the substance was retained by the membrane. The recovery value decreased with decreasing $\mathrm{pH}$, and the lowest percentage of the recovered substance was measured at $\mathrm{pH}=3$ and it was $\mathrm{R}=51.93 \%$. In case of weak acids, such as ketoprofen, the proportion of non-ionized substance is increased at $\mathrm{pH}$ values below $\mathrm{pKa}$, i.e. $\mathrm{pH}$ of 3.0 in this case. The increased portion of non-ionized substance makes this substance more lipophilic and thus has a higher affinity for the lipophilic membrane.

When analysing the obtained values of apparent permeation coefficients from Table 1, it can be noticed that unlike recovery values, $P_{\text {app }}$ did not have a linear growth with $\mathrm{pH}$ values. The lowest mean value of the apparent permeation coefficient $\left(P_{\mathrm{app}}=6.95 \pm 0.51 \times 10^{-5} \mathrm{~cm} \mathrm{~s}^{-1}\right)$ was at $\mathrm{pH}=7.4$. Regardless of the fact that the recovery value at this $\mathrm{pH}$ shows the highest percentage, and $P_{\text {app }}$ is the lowest, such results are consistent with the results obtained in the original method. In the original $P_{\text {app }}$ method, the value for ketoprofen at $\mathrm{pH}=7.4$ was $4.27 \pm 0.08 \times 10^{-5} \mathrm{~cm} \mathrm{~s}^{-1}$ and $R=99.1 \%$ [15]. The apparent permeation coefficient showed the highest values at $\mathrm{pH}=4.5$, which was to be expected given that the maximum permeation of ketoprofen is expected at $\mathrm{pH}$ values that are closest to the $\mathrm{pKa}$ value of the substance, which for ketoprofen has a value of 4.45. This is due to the fact that at this $\mathrm{pH}$ value there is a higher ratio of non-ionized substance, which permeates, compared to higher $\mathrm{pH}$ values, and, on the other hand, there is less retention in the membrane compared to lower $\mathrm{pH}$ value that is bellow $\mathrm{pKa}$ value, probably due to the larger portion of the ionized form. The apparent permeation coefficient was $41.6 \pm 1.67 \times 10^{-5} \mathrm{~cm} \mathrm{~s}^{-1}$. This result confirmed the high permeability of ketoprofen, and is in line with the fact that ketoprofen is a weak acid, the absorption of which is expected at a weakly acidic to neutral $\mathrm{pH}$ values. Measurement with phosphate buffer in the donor compartment having a $\mathrm{pH}$ of 6.8 resulted in a $P_{\text {app }}$ value of $16.8 \pm 1.1 \times 10^{-5}$ $\mathrm{cm} \mathrm{s}^{-1}$. These values correlate with all the above facts related to the permeation properties of ketoprofen. At $\mathrm{pH}=3.0$, the mean $P_{\text {app }}$ value obtained was $12.9 \pm 0.28 \times 10^{-5} \mathrm{~cm} \mathrm{~s}^{-1}$. These results were expected, and it is assumed that if there was no increased affinity of the substance and the membrane, it would be even higher at this $\mathrm{pH}$ value.

Table 2. Experimentally obtained apparent permeation coefficients of ketoprofen $\left(\mathrm{cm} \mathrm{s}^{-1}\right)$ at different $\mathrm{pH}$ values and literature data obtained by other methods.

\begin{tabular}{ccccccc}
\hline $\mathbf{p H}$ & $\boldsymbol{P}_{\mathrm{app}} \pm \mathrm{SD}\left(\times \mathbf{1 0} \mathbf{0}^{-5}\right)$ & $\mathbf{F a} \%^{\mathrm{a}}$ & $\boldsymbol{P}_{\mathrm{app}} \pm \mathrm{SD}\left(\times \mathbf{1 0} \mathbf{0}^{-5}\right)^{\mathrm{b}}$ & $\boldsymbol{P}_{\mathrm{app}} \pm \mathrm{SD}\left(\times \mathbf{1 0 ^ { - 5 }}\right)^{\mathrm{c}}$ & $\boldsymbol{P}_{\text {eff }} \pm \mathrm{SD}\left(\times \mathbf{1 0 ^ { - 5 }}\right)^{\mathrm{d}}$ & $\log \boldsymbol{D}^{\mathrm{e}}$ \\
\hline $\mathbf{3 . 0}$ & $12.9 \pm 0.28$ & $/$ & $/$ & $/$ & $/$ & $/$ \\
$\mathbf{4 . 5}$ & $41.6 \pm 1.67$ & 99.9 & $6.02 \pm 2.4^{* *}$ & $/$ & $/$ & $1.8^{* *}$ \\
$\mathbf{6 . 8}$ & $16.8 \pm 1.1$ & 100 & $1.86 \pm 1.5^{* * *}$ & $26.0 \pm 13.4^{* * *}$ & $29.2 \pm 0.7^{* * *}$ & 0.8 \\
$\mathbf{7 . 4}$ & $6.95 \pm 0.5$ & 100 & $0.24 \pm 0.7$ & $15.8 \pm .24$ & $23.5 \pm 0.7$ & 0.1
\end{tabular}

${ }^{\mathrm{a}}$ Values of simulated Fa (dose fraction absorbed in humans) [18]; ${ }^{\mathrm{b}}$ BML-PAMPA (biomimetic lipid parallel artificial membrane permeability assay) $P_{\text {app }}$ values [19]; ${ }^{C} P_{\text {app }}$ values obtained by Ussing chambers' model [20]; ${ }^{d}$ SPIP $P_{\text {eff }}$ (effective permeation coefficient) values [20]; ${ }^{\mathrm{e}} \log D$ (distribution coefficient) values $[20,21] ;{ }^{*}$ Values at $\mathrm{pH}=2 ;{ }^{* *}$ Values at $\mathrm{pH}=5.5 ;{ }^{* * *}$ Values at $\mathrm{pH}=6.5$

Numerous methods for testing absorption/permeation have been described in the literature. Table 2 shows the literature accounts of experimentally obtained values of other methods for testing the permeation of ketoprofen at certain $\mathrm{pH}$ values, as well as the literature values of the in silico simulated dose fraction absorbed in humans $(\mathrm{Fa})$, and $\log D$. The correlations between the obtained results and these 
literature data were examined. In general, this type of testing referring to $\mathrm{pH}$ dependence is scarce and lacking.

Due to the lack of experimental data on the permeation coefficients of ketoprofen at the exact same $\mathrm{pH}$ values, the values at approximate $\mathrm{pH}$ were taken for certain parameters, as indicated in the Legend of Table 2.

Dose fraction absorbed in humans of ketoprofen is $90 \%$, and it is mainly absorbed in the small intestine [5]. However, due to the lack of $\mathrm{pH}$ dependent data on its in vivo absorption, the obtained results cannot be compared or correlated. The results were compared with the available results of in silico simulated fraction of the dose absorbed in humans at different $\mathrm{pH}$ values and gave the correlation factor of $R^{2}=$ 0.9239 .

The comparisons of the results of in situ and ex vivo models [20] were possible only at two pH values, namely $\mathrm{pH}=6.8$ and $\mathrm{pH}=7.4$, so it was not purposeful to calculate the correlation coefficient. However, the trend of increasing permeation with decreasing $\mathrm{pH}$ of the environment in both cases was evident (Table 2). The same trend was present for the BML-PAMPA assay and $\log D$ results, even taking into consideration that the $\mathrm{pH}$ was different near $\mathrm{pKa}$ of ketoprofen in the two experiments.

Comparison of the obtained results with the results of Corti et al. [15] and our earlier results [16] was not possible due to the lack of data on apparent permeation coefficients for all $\mathrm{pH}$ values.

\section{Permeation of metformin dependent on the $\mathrm{pH}$ of the donor solution}

The metformin permeation profiles' parameters at different $\mathrm{pH}$ of the donor compartment are presented in Table 3 and Figure 3.

The $\mathrm{pKa}$ value of 11.5 makes metformin a strong base found in non-ionized form in the percentage of only $0.008 \%$ at $\mathrm{pH}$ 7.4. Given the physicochemical properties of metformin ( $\mathrm{pKa}$ values, $\log P$ ) that determine its high solubility and poor permeability, metformin will prevail at physiological $\mathrm{pH}$ in ionized form, which will favor its solubility, but will not favor passive transport. Due to its properties, metformin is mainly absorbed in vivo by active transport via number of transporters located in intestinal membranes [22]. Otherwise, for drugs belonging to BCS class III, it would be possible to establish an in vivo - in vitro correlation if the drug is highly soluble (such as metformin), if it is not subject to the first pass effect and is not metabolized (such as metformin) and if it is not transported by carriers. Since it does not meet the third criterion, it is not possible to establish an in vitro - in vivo correlation for metformin, but it is possible to examine the extent to which passive transport is involved in its permeation and the effects of $\mathrm{pH}$ on this type of permeation.

Table 3. Mean values $(n=3)$ of the apparent permeation coefficients $\left(P_{\text {app }}\right)$ of metformin, the recovery of the substance not retained by the membrane $(R)$ and percentage of calculated (non)ionized species $\left(\mathrm{BH}_{2}{ }^{2+} / \mathrm{BH}^{+} / \mathrm{B}\right)$ at different $\mathrm{pH}$ values of donor compartment.

\begin{tabular}{cccc}
\hline $\mathbf{p H}$ & $\boldsymbol{P}_{\mathrm{app}}\left(\times \mathbf{1 0}^{-8} \mathbf{C m ~ s}^{-1}\right) \pm \mathrm{SD}$ & $\boldsymbol{R}(\%) \pm \mathrm{SD}$ & $\mathbf{B H}_{\mathbf{2}}{ }^{2+} / \mathrm{BH}^{+} / \mathbf{B}(\%)$ \\
\hline $\mathbf{7 . 4}$ & $29.82 \pm 1.095$ & $96.19 \pm 4.92$ & $0.0025 / 99.99 / 0.008$ \\
$\mathbf{6 . 8}$ & $9.83 \pm 0.199$ & $90.00 \pm 2.73$ & $0.010 / 99.99 / 0.002$ \\
$\mathbf{4 . 5}$ & $9.79 \pm 0.234$ & $90.37 \pm 3.20$ & $1.96 / 98.04 / 9.8 \times 10^{-6}$ \\
$\mathbf{2 . 0}$ & $5.53 \pm 0.556$ & $85.31 \pm 4.45$ & $86.32 / 13.68 / 4.33 \times 10^{-9}$ \\
\hline
\end{tabular}




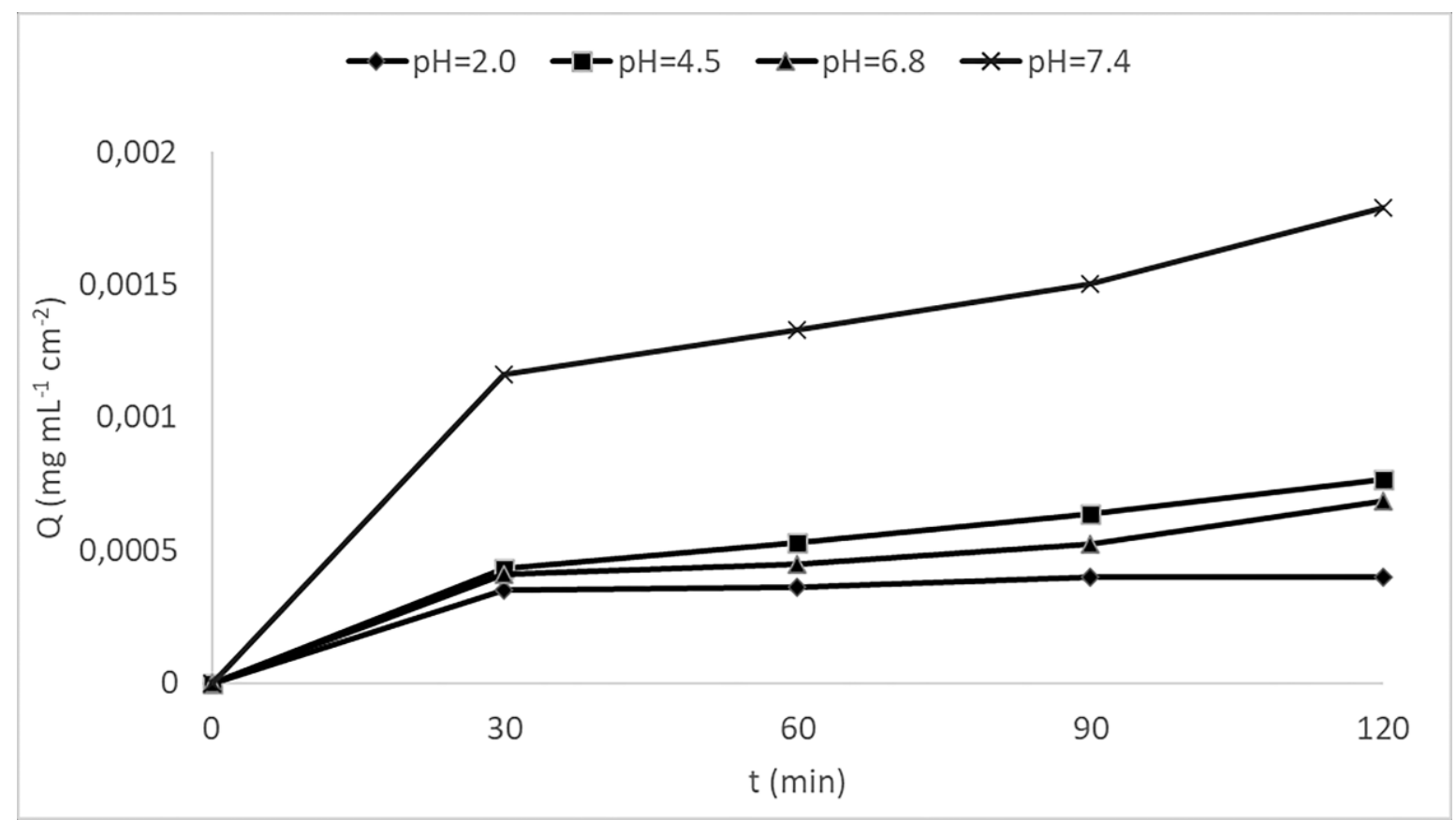

Figure 3. Overall permeated amount of metformin across the artificial membrane at different $\mathrm{pH}$ values of donor compartment.

At $\mathrm{pH} 2.0$ (which corresponds to the gastric $\mathrm{pH}$ ) most of metformin (86.32\%) is in diprotonated form, i.e. it is in the form of a double positively charged ion. In the protonated form, positively charged metformin at this $\mathrm{pH}$ value is present at $13.68 \%$, while the non-ionized form is represented by only $4.33 \times$ $10^{-9} \%$. These data point to the fact that metformin at the $\mathrm{pH}$ value of the stomach is very difficult to passively permeate through physiological membranes, which the obtained results confirm.

Table 3 shows that the $P_{\text {app }}$ value was $5.53 \times 10^{-8} \mathrm{~cm} \mathrm{~s}^{-1}$, very low due to the low permeability of the substance at $\mathrm{pH}$ 2.0. Metformin is at gastric $\mathrm{pH}$, a highly ionized molecule and as such cannot passively permeate through physiological membranes. The recovery value was $85.31 \%$, indicating a higher retention of metformin in the artificial membrane than at other $\mathrm{pH}$ values of the donor compartment, probably due to the affinity of metformin for membrane components made of cellulose nitrate and phospholipids from the impregnation solution.

At $\mathrm{pH} 4.5$, the share of the diprotonated form of metformin is $1.95 \%$, while the single positively charged form dominates $(98.04 \%)$. Non-ionized form of the molecule is present in a percentage of $9.8 \mathrm{x}$ $10^{-6} \%$. Although present in extremely low percentage, the non-ionized form of metformin is still insufficient for unobstructed passive permeation, and the $P_{\text {app }}$ value was $9.79 \times 10^{-8} \mathrm{~cm} / \mathrm{s}$ at this $\mathrm{pH}$. The $\mathrm{pH}$ value of 4.5 is present at the level of the duodenum from where in vivo metformin absorption will start to take place.

At $\mathrm{pH}$ values of 6.8 , metformin is found in the non-ionized form in portion of $0.0019 \%$. Passive permeation in this case is more pronounced than at lower $\mathrm{pH}$ values. Generally, in vivo metformin absorption mainly takes place from GIT regions where the $\mathrm{pH}$ value is 6.8. However, in vivo absorption is aided by a number of protein carriers and transporters located along the length of the intestinal mucosa that facilitate and enable cellular uptake of metformin from the apical to the basolateral membrane of enterocytes. Therefore, an in vitro model based exclusively on passive transport could not adequately map events at physiological $\mathrm{pH} 6.8$, but only the passive component of membrane transport. Since the nonionized content is lower than at $\mathrm{pH} 7.4$, the permeation rate is lower at this $\mathrm{pH}$ of the environment. The mean $P_{\text {app }}$ value shown in Table 3 was $9.83 \times 10^{-8} \mathrm{~cm} \mathrm{~s}^{-1}$. 
At pH 7.4 metformin is present in the non-ionized form $0.008 \%$. Although the concentration of the uncharged form is extremely low, it is the highest at the studied $\mathrm{pH}$ values and as such shows the best permeation rate and extent through the artificial membrane.

The $\mathrm{pH}$ value of the donor compartment was the furthest from the lower $\mathrm{pKa}$ value for metformin (2.8), which favored its existence in non-ionized form, and enabled its passive permeation across the artificial membrane. From the results shown in Table 3, it can be seen that the mean $P_{\text {app }}$ at pH 7.4 was $2.98 \times 10^{-7}$ $\mathrm{cm} \mathrm{s}^{-1}$. Although this permeation rate is low compared to substances that show good permeability, this is the highest value of permeation obtained in this experimental work due to the fact that at these $\mathrm{pH}$ values the highest percentage of non-ionized form is present compared to other studied $\mathrm{pH}$ values. Thus, metformin is a low permeable compound whose absorption is more favored by alkaline pH values (Figure 3). The recovery value of $R=96.19 \%$ (Table 3 ) indicates that metformin mostly uninterruptedly permeated.

In summary, metformin is highly ionized throughout the length of the GIT, which explains its low permeability by passive transport. It also explains the fact that metformin is in BCS class III (high solubility low permeability). Its permeability, as mentioned earlier, is significantly higher in vivo, since it is suggested to be absorbed by active transport through supported carriers [22].

In Figure 3, it can be seen that as the $\mathrm{pH}$ value increases, the slopes of the metformin permeation profile increase, so the highest $P_{\text {app }}$ values were observed at $\mathrm{pH}$ 7.4. At this $\mathrm{pH}$ value, metformin has good solubility, low lipophilicity, and the highest concentration of non-ionized substance compared to the other studied $\mathrm{pH}$ values, thus it more easily permeates into the acceptor compartment with very small percentage of retention in the artificial membrane. The $\log D$ value for metformin is -1.43 , which indicates low solubility in lipids, and thus low affinity for the membrane, which is lipid in nature. As can be seen from Figure 3, after the initial jump in the concentration of permeated metformin after 30 minutes at $\mathrm{pH}$ 2.0, almost a plateau is reached, which can be explained in that the saturation of metformin in the membrane is reached and diprotonated molecules repel each other impeding further permeation through the membrane. This is similar, although less pronounced, at higher $\mathrm{pH}$ values.

The behavior of metformin at $\mathrm{pH}$ values of 6.8 and 4.5 corresponding to the small intestine was shown to be very similar (Figure 3). Even though low permeation rates were observed at both $\mathrm{pH}$ values, permeation of metformin at pH 4.5 physiologically present in the duodenum showed a slight, although insignificant, advantage.

In humans, metformin absorption is incomplete and bioavailability shows interindividual variability at $55 \pm 16 \%$. Absorption ceases 6 - 10 hours after administration, regardless of the amount of metformin administered, which is approximately the time of passage of the drug through the stomach and small intestine [27]. Human data are lacking in $\mathrm{pH}$ dependent transport across the GIT membranes, and thus cannot be further discussed.

Lassoued et al. [23] in their comparative study of permeation of metformin by the Sartorius SM 16750 absorption simulator model and inverted sac technique showed a good correlation in the determination of metformin permeability.

The results of the study conducted by Song et al. [24] concluded that metformin is transported via saturable carriers. The results were not correlated with dynamic diffusion cell model due to the difference in the used methods. 
Table 4. Experimentally obtained apparent permeation coefficients $\left(\mathrm{cm} \mathrm{s}^{-1}\right)$ of metformin at different $\mathrm{pH}$ values and literature data obtained by other methods.

\begin{tabular}{|c|c|c|c|c|c|c|c|c|c|}
\hline $\mathrm{pH}$ & $P_{\mathrm{app}} \pm \mathrm{SD}\left(\times 10^{-6}\right)$ & $\begin{array}{c}P_{\mathrm{app}} \pm S D^{\mathrm{a}} \\
\left(\times 10^{-6}\right)\end{array}$ & $\begin{array}{c}P_{\text {app }} \pm S D^{a} \\
\left(\times 10^{-6}\right)\end{array}$ & $\begin{array}{c}P_{\text {app }} \pm \mathrm{SD}^{\mathrm{b}} \\
\left(\times 10^{-6}\right)\end{array}$ & $\begin{array}{c}P_{\text {app }} \pm S^{b} \\
\left(\times 10^{-6}\right)\end{array}$ & $\begin{array}{c}P_{\text {eff }} \pm S D^{c} \\
\left(\times 10^{-6}\right)\end{array}$ & $\log D^{d}$ & $\begin{array}{c}P_{\text {app }}^{d} \\
\left(\times 10^{-6}\right)\end{array}$ & $\begin{array}{c}P_{\text {app }} \pm S D^{\mathrm{e}} \\
\left(\times 10^{-6}\right)\end{array}$ \\
\hline 2.0 & $0.055 \pm 0.006$ & / & / & / & / & / & / & / & / \\
\hline 4.5 & $0.098 \pm 0.002$ & / & / & / & / & $\begin{array}{c}45.1 \pm 10.8 \\
\text { (duodenum) }\end{array}$ & -1.41 & / & / \\
\hline 6.8 & $0.098 \pm 0.002$ & $\begin{array}{c}V \\
0.74 \pm 0.15\end{array}$ & $\begin{array}{c}S \\
0.61 \pm 0.1\end{array}$ & / & / & $\begin{array}{c}32.6 \pm 7.3 \\
\text { (jejunum) } \\
29.6 \pm 3.6 \\
\text { (ileum) }\end{array}$ & $\begin{array}{l}-1.30 \\
-1.31\end{array}$ & / & $0.50 \pm 0.057$ \\
\hline 7.4 & $0.298 \pm 0.011$ & / & / & $\begin{array}{c}A \\
8.6 \pm 1.4\end{array}$ & $\begin{array}{c}\text { B } \\
10.9 \pm 1.9\end{array}$ & / & -1.23 & 5.5 & / \\
\hline
\end{tabular}

$\bar{a}$ Values $P_{\text {app }}$ obtained by inverted sac and Sartorius model [23]; ${ }^{b}$ Values $P_{\text {app }}$ obtained on the same Sartorius model with the same experimental conditions with impregnation solution variation [16]; 'Values $P_{\text {app }}$ obtained on isolated duodenum, jejunum and ileum segments in Caco-2 cell model [24]; ${ }^{\mathrm{d}}$ Values $\log D$ and $P_{\text {app }}$ obtained by Caco-2 cell model [25]; ${ }^{\mathrm{e}}$ Values $P_{\text {app }}$ obtained by Caco-2 cell model [26]

However, in the study conducted by Nicklin et al. using the Caco-2 model it was concluded that metformin is transported in the Caco-2 monolayer by passive, unsaturable transport [25]. The hydrophilicity and molecular weight of metformin determined the $P_{\text {app }}$ value of $5.5 \times 10^{-6} \mathrm{~cm} \mathrm{~s}^{-1}$, which is comparable with the results of other hydrophilic high molecular weight compounds tested by the Caco-2 model [28], but also with the results obtained in this experimental work at the same pH values (Table 4). On the other hand, in the Caco-2 cell model study conducted by Proctor et al. [26] the transport and absorption of metformin took place via saturable transport mechanisms. The relative contribution of transcellular and paracellular transport of metformin at a concentration of $0.05 \mathrm{mM}$ was estimated at $9 \%$ and $91 \%$, respectively [26].

Log $D$ values at the studied $\mathrm{pH}$ were below 0.5 which implies poor permeability of metformin within the physiological $\mathrm{pH}$ range prevailing at the GIT level, which is in line with the obtained results. However, the correlation of the results with the available $\log D$ values was very poor $\left(R^{2}=0.63\right)$.

\section{Conclusions}

Ketoprofen is a highly permeable acid, while metformin is dibasic substance with low permeability. pH dependent passive transport through an artificial biomimetic membrane of both substances could be explained by their ionization properties at studied $\mathrm{pH}$ values of donor compartments. $\log D$ values of ketoprofen correlated well, while those of metformin did not. The literature accounts of $\mathrm{pH}$ dependent permeation/absorption are scarce. However, when considering those available, the results correlated well with the other in vitro studies.

The dynamic diffusion cell model has proven to be an efficient, reproducible and simple method for predicting the permeation of ketoprofen. This model examines passive transport across the membrane, and for substances that are absorbed by other forms of transport, such as metformin, this method can be used to predict only its passive transport component.

The dynamic diffusion cell model is a good foundation for future research as a valuable resources-saving screening tool for the new drug candidates at the beginning stages of their development, as well as for known substances permeation elucidation, especially considering its potential for testing at wide range of $\mathrm{pH}$ conditions, which is very difficult by other methods. 
Conflict of interest: The authors declare no conflict of interest.

\section{References}

[1] G. Corti, F. Maestrelli, M. Cirri, S. Furlanetto, P. Mura. Development and evaluation of an in vitro method for prediction of human drug absorption assessment of artificial membrane composition, European Journal of Pharmaceutical Sciences 27 (2006) 346-353. https://doi.org/10.1016/ j.ejps.2005.11.004.

[2] G.L. Amidon, H. Lennernas, V.P. Shah, J.R. Crison. A theoretical basis for a biopharmaceutic drug classification: the correlation of in vitro drug product dissolution and in vivo bioavailability, Pharmaceutical Research 12 (1995) 413-420. https://doi.org/10.1023/a:1016212804288.

[3] A. Avdeef. Physicochemical Profiling (Solubility, Permeability and Charge State), Current Topics in Medicinal Chemistry 1 (2001) 277-351. https://doi.org/10.2174/1568026013395100.

[4] H. Lennernas. Intestinal permeability and its relevance for absorption and elimination, Xenobiotica 37 (2007) 1015-1051. https://doi.org/10.1080/00498250701704819.

[5] I. Shohin, J. Kulinich, G. Ramenskaya, B. Abrahamsson, S. Kopp, P. Langguth, J. Polli, V. Shah, D. Groot, D. Barends, J. Dressman. Biowaiver Monographs for Immediate-Release Solid Oral Dosage Forms: Ketoprofen, Journal of Pharmaceutical Sciences $101 \quad$ (2012) 3593-3603. https://doi.org/10.1002/ips.23233.

[6] C.-L. Cheng, L. X. Yu, H.-L. Lee, C.-Y. Yang, C.-S. Lue, C.-H. Chou. Biowaiver extension potential to BCS Class III high solubility-low permeability drugs: Bridging evidence for Metformin immediate-release tablet, European Journal of Pharmaceutical Sciences 22 (2004) 297-304. https://doi.org/10.1016/i.eips.2004.03.016.

[7] J. Sheng, N. A. Kasim, R. Chandrasekharan, G. L. Amidon. Solubilization and dissolution of insoluble weak acid, ketoprofen: Effects of pH combined with surfactant, European Journal of Pharmaceutical Sciiences 29 (2006) 306-314. https://doi.org/10.1016/j.ejps.2006.06.006.

[8] J.E. Gunton, P.J. Delhanty, S. Takahashi, R.C. Baxter. Metformin rapidly increases insulin acceptor activation in human liver and signals preferentially through insulin-acceptor substrate-2, Journal of Clinical Endocrinology and Metabolism 88 (2003) 1323-1332. https://doi.org/10.1210/jc.2002$\underline{021394}$

[9] G.S. Clarke, A.E. Bretnall, Metformin hydrochloride, in Analytical profiles of drug substances and excipients, H.G. Brittain, Ed., Academic Press, San Diego, CA, USA, 1998, 243-284 ISBN: 9780122608254.

[10] P. Berben, A. Bauer-Brandl, M. Brandl, B. Faller, G.E. Flaten, A.C. Jacobsen, J. Brouwersa, P. Augustijns. Drug permeability profiling using cell-free permeation tools: Overview and applications, European Journal of Pharmaceutical Sciences 119 (2018) 219-233. https://doi.org/ 10.1016/j.ejps.2018.04.016.

[11] D.A. Volpe, Drug permeability studies in regulatory biowaiver applications, in Drug absorption studies, Biotechnology: Pharmaceutical Aspects, C. Ehrhardt, K.J. Kim, Eds., Springer, Boston, MA, USA, 2008, 665-680. https://doi.org/10.1007/978-0-387-74901-3 28.

[12] A. Avdeef, Solubility, Permeability, and Charge State, in Absorption and Drug Development, $2^{\text {nd }}$ ed., A. Avdeef, Ed., John Wiley \& Sons, Inc., New Jersey, USA, 2012, 116-246. https://doi. .org/10.1002/9781118286067.

[13] R. Joubert, J.D. Steyn, H.J. Heystek, J.H. Steenekamp, J.L. Du Preez, J.H. Hamman. In vitro oral drug permeation models: the importance of taking physiological and physico-chemical factors into consideration, Expert Opinion on Drug Delivery 14 (2016) 179-187 https://doi.org/ 10.1080/17425247.2016.1211639.

[14] D. Manallack, R. Prankerd, G. Nassta, O. Ursu, T. Oprea, D. Chalmers. A Chemogenomic Analysis of Ionization Constants-Implications for Drug Discovery, ChemMedChem 8 (2013) 242-255. https://doi.org/10.1002/cmdc.201200507. 
[15] G. Corti, F. Maestrelli, M. Cirri, N. Zerrouk, P. Mura. Development and evaluation of an in vitro method for prediction of human drug absorption II Demonstration of the method suitability, European Journal of Pharmaceutical Sciences 27 (2006) 354-362. https://doi.org/10.1016/ j.ejps.2005.11.005.

[16] A. Elezović, J. Hadžiabdić, E. Vranić, O. Rahić, A. Elezović (2019): Pilot Study On Variation Of Dynamic Diffusion Cell Artificial Membrane Method For The Assessment Of Active Substances Permeability, Research Journal of Pharmaceutical, Biological and Chemical Sciences 10 (2019) 64-75. https://doi.org/10.33887/ripbcs/2019.10.3.9.

[17] International Council for Harmonization of Technical Requirements for Pharmaceuticals for Human Use: Validation of Analytical Procedures: Text and Methodology - Q2(R1) (2005).

[18] Y. Tsume, P. Langguth, A. Garcia-Arieta, G.L. Amidon. In silico prediction of drug dissolution and absorption with variation in intestinal pH for BCS class II weak acid drugs: ibuprofen and ketoprofen, Biopharmaceutical Drug Disposition 33 (2012) 366-377. https://doi.org/10.1002/bdd.1800.

[19] K. Sugano, H. Hamada, M. Machida, H. Ushio, K. Saitoh, K. Terada. Optimized conditions of biomimetic artificial membrane permeation assay, International Journal of Pharmaceutics 228 (2001) 181-188. https://doi.org/10.1016/s0378-5173(01)00845-6.

[20] C. Roos, D. Dahlgren, E. Sjögren, C. Tannergren, B. Abrahamsson, H. Lennernäs. Regional Intestinal Permeability in Rats: A Comparison of Methods, Molecular Pharmaceutics 14 (2017) 4252-4261. https://doi.org/10.1021/acs.molpharmaceut.7b00279.

[21] Y.E. Arnold, J. Thorens, S. Bernard, Y.N. Kalia. Drug Transport across Porcine Intestine Using an Ussing Chamber System: Regional Differences and the Effect of P-Glycoprotein and CYP3A4 Activity on Drug Absorption, Pharmaceutics 11 (2019) 139. https://doi.org/10.3390/pharmaceutics11030139.

[22] A.J. Scheen. Clinical pharmacokinetics of metformin, Clinical Pharmacokinetics 30 (1996) 359-371. https://doi.org/10.2165/00003088-199630050-00003.

[23] M.A. Lassoued, F. Khemiss, S. Sfar. Comparative Study of Two In Vitro Methods for Assessing Drug Absorption: Sartorius SM 16750 Apparatus Versus Everted Gut Sac, Journal of Pharmacy and Pharmaceutical Sciences 14 (2011) 117 - 127. https://doi.org/10.18433/i3gc7r.

[24] N.N. Song, Q.S. Li, C.X. Liu. Intestinal permeability of metformin using single-pass intestinal perfusion in rats, World Journal of Gastroenterology 12 (2006) 4064-4070. https://doi.org/10.3748/wig. v12.i25.4064.

[25] P. Nicklin, A.C. Keates, T. Page, C.J. Bailey. Transfer of metformin across monolayers of human intestinal Caco-2 cells and across rat intestine, International Journal of Pharmaceutics 128 (1996) 155-162. https://doi.org/10.1016/0378-5173(95)04259-8.

[26] W.R. Proctor, D.L. Bourdet, D.R. Thakker. Mechanisms underlying saturable intestinal absorption of metformin, Drug Metabolism and Disposition 36 (2008) 1650-1658. https://doi. org/10.1124/dmd.107.020180.

[27] G.G. Graham, J. Punt, M. Arora, R.O. Day, M.P. Doogue, J.K. Duong, T.J. Furlong, J.R. Greenfield, L.C. Greenup, C.M. Kirkpatrick, J.E. Ray, P. Timmins, K.M. Williams. Clinical Pharmacokinetics of Metformin, Clinical Pharmacokinetics 50 (2011) 81-98. https://doi.org/10.2165/11534750000000000-00000.

[28] J. Karlsson, P. Artursson. A method for the determination of cellular permeability coefficients and aqueous boundary layer thickness in monolayers of intestinal epithelial (Caco-2) cells grown in permeable filter chambers, International Journal of Pharmaceutics 71 (1991) 55-64. https://doi.org/10.1016/0378-5173(91)90067-X. 